\title{
Evaluating Perceptions of the Healthcare Providers Concerning Accreditation in Healthcare Organizations in the R. Macedonia*
}

\author{
Aneta Petrusevska, Elena Kjosevska, Rosalinda Isjanovska, Beti Zafirova, Mome Spasovski \\ University of Ss Cyril and Methodius, Skopje, Republic of Macedonia \\ Elizabeta Zisovska \\ Agency for Quality and Accreditation of Healthcare Organizations, Skopje, Republic of Macedonia
}

\begin{abstract}
An important factor for successful implementation of accreditation is readiness of the healthcare organization for organizational changes. This study aims at assessing perceptions of the medical staff in healthcare organizations, regarding organizational changes related to accreditation, before starting the national accreditation in hospitals in $\mathrm{R}$. Macedonia and to interconnect variables with the implementation of the process. A prospective cross-sectional study was conducted, performed in healthcare organizations throughout the R. Macedonia. Main tool for the study was a questionnaire consisting of seven questions of a closed type. Variables such as changes in line with law and regulations, introducing a new informational system, improving the working conditions, are perceived by the majority of the respondents as drivers toward successful implementation of the process. Conversely, high percent of the respondents find positive changes happen without introducing accreditation. Personnel is not certain who leads the changes and if resistance to change exists depending on not finding significance to answers yes, no, and the category without answer. For the majority of the respondents, accreditation is an effective tool for implementing changes that lead to quality in their organization.
\end{abstract}

Keywords: accreditation, organizational changes, perceptions of healthcare staff, healthcare organizations

\footnotetext{
* The authors would thank Mayer Brezis (MD, MPH), Professor of Medicine Center for Clinical Quality and Safety Hadassah Hebrew University Medical Center, who with his helpful comments and suggestions contributed a great deal to this paper.

Corresponding author: Aneta Petrusevska, MD, dermatovenerologist, Clinic Dr. Ancevski; research fields: public health, health policies, health care management, quality and accreditation. E-mail: anetakokaleska@gmail.com.

Elena Kjosevska, MD, Ph.D., associate professor, Institute of Social Medicine, Medical Faculty, University of Ss Cyril and Methodius, Skopje; research fields: public health, health policies, health care systems, social medicine, chronic non-communicable diseases, and health promotion. E-mail: kosevska@yahoo.com.

Rosalinda Isjanovska, MD, Ph.D., professor, Institute for Biostatistics, Epidemiology and Medical Informatics, Medical Faculty, University of Ss Cyril and Methodius, Skopje; research fields: biostatistics, epidemiology, and medical informatics. E-mail: prof.isjanovska@gmail.com.

Beti Zafirova, MD, Ph.D., professor, Institute for Biostatistics, Epidemiology and Medical Informatics, Medical Faculty, University of Ss Cyril and Methodius, Skopje; research fields: biostatistics, epidemiology, and medical informatics. E-mail: betizafirova@yahoo.com.

Mome Spasovski, MD, Ph.D., professor, Institute of Social Medicine, Medical Faculty, University of Ss Cyril and Methodius, Skopje; research fields: public health, health policies, health care systems, social medicine, chronic non-communicable diseases, and health care finances and management.E-mail: mome_spasovski@yahoo.com.

Elizabeta Zisovska, MD, Ph.D., professor, Agency for Quality and Accreditation of Healthcare Organizations in R. Macedonia; research fields: public health, health policies, health care management, quality and accreditation. E-mail: elizabeta.zisovska@ugd.edu.mk.
} 
Accreditation in the healthcare sector was implemented for the first time in hospitals in the United States in 1951 (Braithwaite et al., 2011). Over time, it has been positioned internationally very well (Greenfield, Pawsey, \& Braithwaite, 2010) and is embraced in more than 70 countries around the world. The largest international body associated with accreditation is the International Association for Quality in Health Care (ISQua) (Greenfield \& Braithwaite, 2008). This internationalization that occurs in healthcare, allows exchange of health services, technology, communication, transfer of data and professionals between countries, in order to meet the requirements for a high level of health care delivery (Moe, Pappas, \& Murray, 2007).

Accreditation is based on the assumption that adherence to predetermined standards based on evidence, ensures higher quality and increases security in provision of healthcare services in a health organization. The process of accreditation usually is performed in three sub-activities: self-evaluation of performance within the organization, assessment of matching with standards that is performed by an accreditation body or agency and final accreditation report that assesses the performance of the organization along with recommendations for improvement (Braithwaite et al., 2011). It is envisaged that after a specified period of time, a re-accreditation is to be performed as means to verify sustaining and improving of the standards, after which the accreditation status is prolonged or revoked (Braithwaite et al., 2011).

Accreditation as a tool for implementing and continuous improving of quality in healthcare organizations is achieved through numerous accreditation programs and organizations at national and international level. Every country has a different regulated policy for enforcing accreditation in healthcare organizations. In some countries, it is on voluntary ground, in others, it is a law obligation or other ways of its officialization are found such as: through a law of licensing like in Austria and Estonia, an obligation that hospitals define legislation for minimum medical competencies like in Belgium, developing a national accreditation program with mandatory minimum standards like in Columbia, through an independent specialty based program under national law who accredits all health services like in France, national law which has required accreditation to be established by regional governments which define their own model and standards based on national standards like in Italy or the case with Thailand where accreditation is more an educational tool rather than an inspection scheme ${ }^{1}$.

Inspection and standard setting processes have been placed in many industries (Braithwaite et al., 2006) besides healthcare. By acceptance of clearly defined standards, greater control and greater internal organization of work can be achieved. Accreditation is intended to create regulation in the organization through the adoption of certain rules and by creating a specific relation between the processes and structures (Alkhenizan $\&$ Shaw, 2011) in the environment in which that work is carried out. Through accreditation not only corresponds with determined national indicators for performance becomes more transparent, but the accreditation process tends to involve more of the clinical components incorporating indicators of clinical performance (Collopy, 2000). The goal is emphasis on the key message that the health organization delivers' products or services are acceptable to consumers, funders, and stakeholders (Braithwaite et al., 2006). Accreditation is a way to publicly acknowledge that the health organization deserves the benchmark of quality, reflecting the individual and organizational performance in a given healthcare organization (Braithwaite et al., 2006). In societies where it is not introduced, there lacks a way of evaluating and monitoring for quality of services delivered to patients.

\footnotetext{
${ }^{1}$ Quality and accreditation in health care services-A global review. Retrieved from http://www.who.int/hrh/documents/ en/quality_accreditation.pdf.
} 


\section{Accreditation of Healthcare Organizations in R. Macedonia}

The health care system in the Republic of Macedonia is in its final preparation phase for commencing the process of accreditation of healthcare organizations. In July 2014, an agency for accreditation ${ }^{2}$ was established by the Government of the R. Macedonia. The agency for accreditation prepared national accreditation standards which recently have been accepted by the Government of the R. Macedonia, as have already done 28 countries which have established their own hospital accreditation systems (Huang, Hsu, Kai-Yuan, \& Hsueh, 2000). The process of accreditation is expected to begin in public health institutions at tertiary health care level, gradually to encompass all of the health system, in both the public and private sector. Before the start of this research, no hospital or other health institution as a whole, giving medical care and services either primary, secondary or tertiary has accomplished accreditation by any standard in R. Macedonia. The period before the introduction of accreditation in health care not only in R. Macedonia but in all countries that are preparing to undertake such a step, it is particularly vulnerable in the context of issues concerning willingness of staff toward organizational changes, accepting certain standards and if they, by the perceptions of the staff, will lead to quality, do they provoke resistance or not, and what general changes induced by the accreditation process, by the opinion of staff, lead to quality.

Health organizations implement changes in order to achieve better quality, and for changes to be successful, it is crucial that they be accepted by the biggest possible number of employees in a healthcare organization.

This study aims at assessing the perceptions of the medical personnel in healthcare organizations, pertained to organizational changes related to accreditation, in a period just before starting the national accreditation in hospitals in R. Macedonia and to interconnect certain variables with the implementation of this process. This research on perceptions and attitudes of the medical team regarding organizational change in relation to accreditation, before introducing national accreditation of hospitals by law, is among the first of its kind in the Republic Macedonia. In the academic literature, there are very few published studies covering the period before introduction of accreditation.

\section{Method and Design of the Study}

A descriptive and analytical prospective cross-sectional study was conducted, performed in healthcare organizations throughout the R. Macedonia.

\section{Determination of Sample}

The participating health care organizations were obtained by convenience sample. In the study, 17 healthcare organizations took part, including two private healthcare institutions and 15 public healthcare institutions. Out of the 17 organizations, there were seven hospitals, 10 clinics and institutes. A total number of 700 questionnaires were divided, and 402 healthcare workers filled in the questionnaire (the number of needed respondents was calculated to be between 400 and 500, using the formula $C=1 / \sqrt{ } 400 \times 100$ ). The research was conducted in duration of four months September-December 2014.

\section{Criteria for Inclusion and Exclusion}

Criteria for inclusion of the health organizations were: organizations that have not yet started or completed the process of accreditation and are either public or private institutions providing tertiary care to patients. Tertiary care means that the organization has a determined number of beds for in-patients. Inclusion criteria for

\footnotetext{
${ }^{2}$ Institute for Accreditation of R. Macedonia. Retrieved from https://www.iarm.gov.mk.
} 
staff were that they be healthcare providers, i.e., doctors, nurses, and technicians. Criteria for exclusion were: organizations that launched or completed the process of hospital accreditation.

\section{The Survey Instrument}

For the purpose of this research, a special questionnaire was designed. In designing the questionnaire, parts and modified parts of previously prepared internationally renowned questionnaires were used (Ripley, 2007; Drew, 2005; Tosh, 2006), as well as specially designed questions in order to achieve the objectives of the research. This research is a part of a larger questionnaire, designed to meet the objectives of the survey of the doctoral dissertation of the author of this paper. This section consisted of a set of demographic questions (gender, age, and professional function) and seven close-ended questions. The data were obtained through completion of the questionnaire by the healthcare givers. After the completion of the activities on the field and check for quality of the completed questionnaires, they were coded and fully processed.

\section{Statistical Tools}

Statistical analysis of data was carried out in the statistical program SPSS 17.0 for Windows. The analyzed variables because of their qualitative character are shown in absolute and relative numbers. Testing differences in responses between the analyzed groups were performed with Pearson chi-square test, binary logistic regression as a prediction of effective accreditation and cross tabulation using Pearson chi-square test. The value of $\mathrm{p}<0.05$ was considered statistical significant, and $\mathrm{p}<0.01$ for statistically highly significant.

\section{Ethical Aspects}

The survey was conducted on the basis of confidentiality, anonymity, and voluntary participation. All participants received a written explanation for the reasons for the investigation and for the steps taken to preserve their anonymity. Understanding the objectives of the research and the will to conduct the interview are the components of the voluntary compliance. Written informed consent was not required to preserve the anonymity of the participants. None of the reports prepared on the basis of data obtained from the study contain information to identify any of the participants.

\section{Results}

\section{Demographic Data}

Total number of the participants in the study was 402 healthcare workers from 17 healthcare organizations, two privately owned, and the remaining 15 public health institutions delivering tertiary care (hospitals, clinics, and institutes). The number of employees in any organization was between 34 and 720 . The number of beds in each organization was between 18 and 450 .

The gender structure of respondents presented with 122 (30.3\%) male and 273 (67.9\%) female respondents. The age group from 31 to 45 years was dominant with 183 (45.5\%) respondents.

In terms of professional function performed in the organization, the distribution table shows that the majority of respondents $-44.3 \%$ have a university degree, doctor, followed by respondents with high school diploma (nurses, laboratory technicians) $-30.1 \%$, while $12.7 \%$ physicians performing managerial functions (see Table 1).

Distribution regarding gender, the highest percent was female-67.9\%. Most present age group was between 31 and 45 years and highest percent regarding professional function was with faculty diploma-doctor (4.3\%), and high school diploma—nurse, technician, and lab technician (30.1\%). 
Table 1

Distribution of Respondents According to Their Professional Function in the Organization

\begin{tabular}{lll}
\hline Staff/Professional function & Number & Percent (\%) \\
\hline University degree-doctor & 178 & 44.3 \\
Physician with managerial function & 51 & 12.7 \\
High school diploma-nurse, laboratory technician & 121 & 30.1 \\
Other function & 41 & 10.2 \\
Without answer & 11 & 2.7 \\
Total & 402 & 100.0 \\
\hline
\end{tabular}

The analysis of the answers received from respondents (see Table 2) indicated that they have almost identical perceptions regarding the leader of changes in their organization, or $44.5 \%$ think that it is the management, $44.3 \%$ of the healthcare givers and these answers are found significantly $(\mathrm{p}<0.01)$ more often in terms of the response "other".

Respondents significantly $(\mathrm{p}<0.01)$ more often consider changes in their organization are implemented according to law and regulations, compared with changes implemented in line with the impression of self-evaluated weaknesses in the organization and other $(61.4 \%, 27.4 \%$, and $7.7 \%$ consequently).

The need to introduce a new informational system was significantly $(\mathrm{p}<0.01)$ more frequently cited in the responses of the respondents compared with not having the need or without opinion $(61.2 \%, 15.9 \%$, and $21.6 \%)$.

The percentage of respondents who believe that the quality changes in their organization occur without accreditation is $45.3 \%, 18.4 \%$ do not share this opinion and a high percentage of $34.8 \%$ have no opinion. The difference registered between good changes without accreditation in the workplace and good changes due to accreditation attitudes is statistically significant for $\mathrm{p}<0.01$.

Respondents have insignificant different opinion on the existence of resistance toward changes in their organization $(\mathrm{p}=0.09)$.

More than half of the respondents (50.7\%) think that the most important changes as a result of accreditation occur in the working conditions, while the lowest percentage of them say that it in budget reduction (13.4\%). The difference in the distribution of respondents' answers to the most important changes due to accreditation is confirmed as statistically highly significant $(\mathrm{p}<0.01)$.

A big percentage of respondents - $67.4 \%$, believe that accreditation is an effective tool for implementing changes that lead to quality in their organization, only $6.0 \%$ have a negative attitude and $22.9 \%$ are without opinion. The difference registered among these three modalities is statistically confirmed as highly significant for $\mathrm{p}<0.01$.

The authors have analyzed perceptions of the healthcare givers regarding their professional function to variables concerning organizational changes and accreditation (see Table 3). As a major driving force toward changes, in the opinion of participants with high school diploma (nurses, technicians), is management- $52.9 \%$, while doctors with and without managerial function, as well as other employees, consider the professional team as a driver toward changes $(44.57 \%, 47.06 \%$, and $46.34 \%$, consequently). Statistical analysis confirm there is not a significant difference in the views depending on the professional function (Pearson chi-square: $8.36, \mathrm{df}=$ $6, p=0.21)$. 
Table 2

Questions Regarding Attitudes of the Medical Personel About Organizational Changes

\begin{tabular}{ll}
\hline Question & $\mathrm{N}=402(\%)$
\end{tabular}

Who in your opinion is the driving force toward changes in your organization

$\begin{array}{ll}\text { Management } & 179(44.5 \%)\end{array}$

$\begin{array}{ll}\text { Healthcare givers } & 174(43.3 \%)\end{array}$

Other $\quad 44(10.9 \%)$

$\begin{array}{ll}\text { Without answer } & 5(1.3 \%)\end{array}$

Chi-square $=88.5, \mathrm{df}=2, \mathrm{p}<0.01$

What kinds of changes in your opinion are implemented in your organization

In line with impression of self-evaluated weaknesses in the organization $\quad 110(27.4 \%)$

In line with law and other regulations set by relevant institutions $\quad 247(61.4 \%)$

$\begin{array}{ll}\text { Other } & 31(7.7 \%)\end{array}$

$\begin{array}{ll}\text { Without answer } & 14(3.5 \%)\end{array}$

Chi-square $=184.7, \mathrm{df}=2, \mathrm{p}<0.01$

In your opinion, do you think the organization needs to introduce a new information technology (IT) or intranet adapted to the needs of accreditation

\begin{tabular}{ll}
\hline Yes & $246(61.2 \%)$
\end{tabular}

$\begin{array}{ll}\text { No } & 64(15.9 \%)\end{array}$

Without opinion $\quad 87(21.6 \%)$

$\begin{array}{ll}\text { Without answer } & 5(1.3 \%)\end{array}$

Chi-square $=148.4, \mathrm{df}=2, \mathrm{p}<0.01$

In my organization, organizational changes toward quality happen even without implementing the accreditation program

\begin{tabular}{ll}
\hline Yes & $182(45.3 \%)$
\end{tabular}

$\begin{array}{ll}\text { No } & 74(18.4 \%)\end{array}$

$\begin{array}{ll}\text { Without opinion } & 140(34.8 \%)\end{array}$

$\begin{array}{ll}\text { Without answer } & 6(1.5 \%)\end{array}$

Chi-square $=44.9, \mathrm{df}=2, \mathrm{p}<0.01$

In your opinion, does resistance to change exist in your organization

\begin{tabular}{ll}
\hline Yes & $151(37.5 \%)$
\end{tabular}

No $\quad 129(32.1 \%)$

Without opinion $\quad 116(28.9 \%)$

$\begin{array}{ll}\text { Without answer } & 6(1.5 \%)\end{array}$

Chi-square $=4, \mathrm{df}=2, \mathrm{p}=0.09$

Which in your opinion are the most important changes occur due to accreditation

\begin{tabular}{ll}
\hline In the working conditions & $204(50.7 \%)$
\end{tabular}

Budgetary cuts (reduction of deficiency) $\quad 54(13.4 \%)$

Bettering interpersonal relations among employees $\quad 91(22.6 \%)$

Satisfaction of patients/clients $\quad 150(37.3 \%)$

$\begin{array}{ll}\text { Technological improvement } & 129(32.1 \%)\end{array}$

$\begin{array}{ll}\text { Other } & 22(5.5 \%)\end{array}$

$\begin{array}{ll}\text { Without answer } & 13(3.2 \%)\end{array}$

Chi-square $=202.4, \mathrm{df}=5, \mathrm{p}<0.01$

In your opinion, what kind of changes leads to quality? Open-ended question

According to me, accreditation is an effective tool for an organization to implement changes toward quality

\begin{tabular}{ll}
\hline Yes & $271(67.4 \%)$
\end{tabular}

$\begin{array}{ll}\text { No } & 24(6.0 \%)\end{array}$

Without opinion $\quad 92(22.9 \%)$

$\begin{array}{ll}\text { Without answer } & 15(3.7 \%)\end{array}$

Chi-square $=252.4, \mathrm{df}=2, \mathrm{p}<0.01$ 
Table 3

Perceptions of the Healthcare Givers Regarding Professional Function

\begin{tabular}{|c|c|c|c|c|}
\hline \multirow{2}{*}{ Variable } & \multicolumn{4}{|c|}{ Professional function in the organization } \\
\hline & Doctor & Doctor-managerial role & High school & Other function \\
\hline \multicolumn{5}{|c|}{ Who in your opinion is the driving force toward changes in your organization } \\
\hline Management & $71(40.57 \%)$ & $23(45.1 \%)$ & $63(52.94 \%)$ & $16(39.02 \%)$ \\
\hline Healthcare givers & $78(44.57 \%)$ & $24(47.06 \%)$ & $48(40.34 \%)$ & $19(46.34 \%)$ \\
\hline Other & $26(14.86 \%)$ & $4(7.84 \%)$ & $8(6.72 \%)$ & $6(14.63 \%)$ \\
\hline Total & $175(100 \%)$ & $51(100 \%)$ & $119(100 \%)$ & $41(100 \%)$ \\
\hline \multicolumn{5}{|c|}{ Pearson chi-square: $8.36, \mathrm{df}=6, \mathrm{p}=0.21$} \\
\hline \multicolumn{5}{|c|}{ What kind of changes in your opinion is implemented in your organization } \\
\hline $\begin{array}{l}\text { In line with self-evaluated weaknesses } \\
\text { in the organization }\end{array}$ & $53(30.99 \%)$ & $12(23.53 \%)$ & $31(26.72 \%)$ & $10(25 \%)$ \\
\hline $\begin{array}{l}\text { In line with law and other regulations } \\
\text { set by relevant institutions }\end{array}$ & $104(60.82 \%)$ & $37(72.55 \%)$ & $76(65.52 \%)$ & $24(60 \%)$ \\
\hline Other & $14(8.19 \%)$ & $2(3.92 \%)$ & $9(7.76 \%)$ & $6(15 \%)$ \\
\hline Total & $171(100 \%)$ & $51(100 \%)$ & $116(100 \%)$ & $40(100 \%)$ \\
\hline \multicolumn{5}{|l|}{ Pearson chi-square: $5.52, \mathrm{df}=6, \mathrm{p}=0.48$} \\
\hline \multicolumn{5}{|c|}{ In your opinion, do you think the organization needs to introduce a new IT or intranet adapted to the needs of accreditation } \\
\hline Yes & $105(60.34 \%)$ & $33(64.71 \%)$ & $69(57.5 \%)$ & $31(75.61 \%)$ \\
\hline No & $32(18.39 \%)$ & $9(17.65 \%)$ & $18(15 \%)$ & $4(9.76 \%)$ \\
\hline Without opinion & $37(21.26 \%)$ & $9(17.65 \%)$ & $33(27.5 \%)$ & $6(14.63 \%)$ \\
\hline Total & $174(100 \%)$ & $51(100 \%)$ & $120(100 \%)$ & $41(100 \%)$ \\
\hline \multicolumn{5}{|l|}{ Pearson chi-square: $6.62, \mathrm{df}=6, \mathrm{p}=0.36$} \\
\hline \multicolumn{5}{|c|}{ In my organization, organizational changes toward quality happen even without implementing the accreditation program } \\
\hline Yes & $75(43.1 \%)$ & $22(43.14 \%)$ & $63(52.94 \%)$ & $17(41.46 \%)$ \\
\hline No & $39(22.41 \%)$ & $11(21.57 \%)$ & $11(9.24 \%)$ & $11(26.83 \%)$ \\
\hline Without opinion & $60(34.48 \%)$ & $18(35.29 \%)$ & $45(37.82 \%)$ & $13(31.71 \%)$ \\
\hline Total & $174(100 \%)$ & $51(100 \%)$ & $119(100 \%)$ & $41(100 \%)$ \\
\hline \multicolumn{5}{|l|}{ Pearson chi-square: $10.88, \mathrm{df}=6, \mathrm{p}=0.09$} \\
\hline \multicolumn{5}{|c|}{ In your opinion, does resistance to change exist in your organization } \\
\hline Yes & $73(41.71 \%)$ & $20(39.22 \%)$ & $34(28.81 \%)$ & $21(51.22 \%)$ \\
\hline No & $51(29.14 \%)$ & $18(35.29 \%)$ & $44(37.29 \%)$ & $12(29.27 \%)$ \\
\hline Without opinion & $51(29.14 \%)$ & $13(25.49 \%)$ & $40(33.9 \%)$ & $8(19.51 \%)$ \\
\hline Total & $175(100 \%)$ & $51(100 \%)$ & $118(100 \%)$ & $41(100 \%)$ \\
\hline \multicolumn{5}{|l|}{ Pearson chi-square: $9.23, \mathrm{df}=6, \mathrm{p}=0.16$} \\
\hline \multicolumn{5}{|c|}{ Which in your opinion are the most important changes due to accreditation occur } \\
\hline In the working conditions & $84(21.87 \%)$ & $29(7.55 \%)$ & $63(16.41 \%)$ & $25(6.51 \%)$ \\
\hline Budgetary cuts (reduction of deficiency) & $30(7.81 \%)$ & $6(1.6 \%)$ & $13(3.4 \%)$ & $5(1.3 \%)$ \\
\hline $\begin{array}{l}\text { Bettering interpersonal relations among } \\
\text { employees }\end{array}$ & $29(7.55 \%)$ & $10(2.6 \%)$ & $37(9.64 \%)$ & $17(4.43 \%)$ \\
\hline Satisfaction of patients/clients & $60(15.62 \%)$ & $23(5.99 \%)$ & $49(12.76 \%)$ & $18(4.69 \%)$ \\
\hline Technological improvement & $63(16.4 \%)$ & $22(5.73 \%)$ & $23(5.99 \%)$ & $14(4.69 \%)$ \\
\hline Other & $12(3.12 \%)$ & $4(1.04 \%)$ & $4(1.04 \%)$ & $2(0.52 \%)$ \\
\hline \multicolumn{5}{|c|}{ Pearson chi-square: $120.93, \mathrm{df}=87, \mathrm{p}=0.009, \mathrm{p}<0.01$} \\
\hline \multicolumn{5}{|c|}{ According to me, accreditation is an effective tool for an organization to implement changes toward quality } \\
\hline Yes & $116(67.05 \%)$ & $39(78 \%)$ & $83(70.94 \%)$ & $30(75 \%)$ \\
\hline No & $13(7.51 \%)$ & $2(4 \%)$ & $5(4.27 \%)$ & $2(5 \%)$ \\
\hline Without opinion & $44(25.43 \%)$ & $9(18 \%)$ & $29(24.79 \%)$ & $8(20 \%)$ \\
\hline Total & $173(100 \%)$ & $50(100 \%)$ & $117(100 \%)$ & $40(100 \%)$ \\
\hline Pearson chi-square: $3.68, \mathrm{df}=6, \mathrm{p}=0.7$ & & & & \\
\hline
\end{tabular}


The answers of the respondents of the analyzed professional groups to the question of what kinds of changes are implemented in their organization are statistically nonsignificant. Doctors on managerial functions more often than other groups gave the answer that changes regulated by law or other regulation are the most common changes implemented in the organization, but the result is nonsignificant according to the professional function (Pearson chi-square: 5.52, $\mathrm{df}=6, \mathrm{p}=0.48$ ).

The need to introduce a new organizational system suited to the accreditation process is stressed by $60.3 \%$ doctors, $64.7 \%$ doctor managers, $57.5 \%$ nurses and technicians, and $75.6 \%$ of respondents with another function. Differences in the distribution of respondents of the analyzed groups, are insufficient to verify significance according to professional function (Pearson chi-square: 6.62, $\mathrm{df}=6, \mathrm{p}=0.36$ ).

Doctors with or without management function, personnel with high school diploma and those with other functions gave statistically insignificant answers to the question of introducing organizational changes toward quality without implementing the accreditation program (Pearson chi-square: 10.88, $\mathrm{df}=6, \mathrm{p}=0.09$ ). The percentage of respondents who answered affirmatively to this question was $43.1 \%$ in the group doctors without management function, $43.14 \%$ in the group doctors with managerial function, $52.94 \%$ in the nurses and technicians, and $41.46 \%$ in the group with other function.

The difference in the distribution of respondents affirmative and negative to the question "Do you think that there is resistance to change in your organization?" is statistically insignificant (Pearson chi-square: 9.23, $\mathrm{df}=6, \mathrm{p}=0.16)$.

The majority of respondents, doctors with or without managerial function, personnel with a high school diploma and other, think that accreditation is an effective tool for the organization to implement quality changes $(67.05 \%, 78 \%, 70.94 \%$, and $75 \%$, consecutively) .

The differences in the distribution of responses are statistically insignificant according to professional function.

The results of the study showed that professional function performed by the respondents is statistically significant only on their perception to the question where the most important changes occur as a result of accreditation (Pearson chi-square: 120.93, $\mathrm{df}=87, \mathrm{p}=0.009$ ). Doctors without managerial position more often than physicians managers, middle professional staff and employees with other functions consider the most important changes occur in the working conditions $-21.87 \%$, while nurses and technicians more frequently than others think that the most important changes due to accreditation would be in the interpersonal relations- $-9.64 \%$.

The results of binary logistic regression as a prediction of effective accreditation (see Table 4) were as following: Female employees compared with male employees are 3,759 or $95 \%$ CI $(1,599-5,537)$ times more likely to have a positive attitude toward accreditation as an effective tool for quality changes.

Respondents who answered that the driver for change in the organization is someone else, not the management and professional team, are 0.133 or $95 \%$ CI (0.042-0.421) times less likely compared with respondents who believe that the holder of change is the management, to have a positive attitude for accreditation as an effective tool for quality changes.

Respondents who answered that a new information system should not be introduced have 0.065 or $95 \% \mathrm{CI}$ (0.023-0.184) times less chance compared with respondents who find it necessary to introduce a new information system, to have a positive attitude for accreditation as an effective tool for change. 
Table 4

Binary Logistic Regression as a Prediction of Effective Accreditation

\begin{tabular}{|c|c|c|c|c|}
\hline \multirow{2}{*}{ Variable } & \multirow{2}{*}{ Sig. } & \multirow{2}{*}{$\operatorname{Exp}(B)$} & \multicolumn{2}{|c|}{$95 \%$ CI $\operatorname{Exp}(\mathrm{B})$} \\
\hline & & & Lower & Upper \\
\hline \multicolumn{5}{|l|}{ Sex-referent category/male } \\
\hline Female vs. male & $0.002^{* *}$ & 3.759 & 1.599 & 5.537 \\
\hline \multicolumn{5}{|c|}{ Professional function in organization-referent category/doctor } \\
\hline Doctor management vs. doctor & 0.255 & 0.538 & 0.185 & 1.566 \\
\hline High school diploma vs. doctor & 0.851 & 1.175 & 0.218 & 2.321 \\
\hline \multicolumn{5}{|c|}{ Driving force toward changes in organization-referent category/answer management } \\
\hline Expert team vs. management & 0.428 & 0.651 & 0.225 & 1.883 \\
\hline Other vs. management & $0.001^{* *}$ & 0.133 & 0.042 & 0.421 \\
\hline \multicolumn{5}{|c|}{$\begin{array}{l}\text { In your opinion, do you think the organization needs to introduce a new IT or intranet adapted to the needs of } \\
\text { accreditation-referent category/answer yes }\end{array}$} \\
\hline \multicolumn{5}{|l|}{ New IT } \\
\hline No vs. yes & $0.000^{* *}$ & 0.065 & 0.023 & 0.184 \\
\hline Without opinion vs. yes & 0.072 & 0.3 & 0.081 & 1.112 \\
\hline \multicolumn{5}{|c|}{$\begin{array}{l}\text { In my organization, organizational changes toward quality happen even without implementing the accreditation } \\
\text { program-referent category/answer yes }\end{array}$} \\
\hline \multicolumn{5}{|l|}{ Changes without accreditation } \\
\hline No vs. yes & 0.069 & 0.419 & 0.164 & 1.071 \\
\hline Without opinion vs. yes & 0.327 & 1.923 & 0.521 & 7.105 \\
\hline \multicolumn{5}{|c|}{ In your opinion, does resistance to change exist in your organization-referent category/answer yes } \\
\hline No vs. yes & 0.212 & 1.896 & 0.694 & 5.177 \\
\hline Without opinion vs. yes & 0.397 & 1.654 & 0.516 & 5.303 \\
\hline
\end{tabular}

Note. Dependant variable: Accreditation is an effective tool/is not an effective tool ${ }^{* *} \mathrm{p}<0.01$.

\section{Discussion}

Accreditation has a main goal to improving quality of the healthcare organization but healthcare organizations need to adapt to that goal. One important factor for a successful implementation of accreditation is readiness of the health organization for organizational changes. In this study, perceptions of the respondents that drivers of organizational changes - in almost equal percentage are management and the expert team, shows that not in all institutions management is perceived as overtaking the role to implement changes and the team does not perceive them as leaders toward positive changes. However, in practice, positive changes are certainly driven by the management (Braithwaite et al., 2011). The level to which employees can participate in the planning and implementing of such processes is in the power of the management (Pahkin et al., 2014), having in mind that changes to be successful employees need to be involved as much as possible (Braithwaite et al., 2011). Another strong catalyst for change is the legislative regulation (Lichiello \& Madden, 1996) as was stated by most of the surveyed personnel. Catalysts for change have been classified as individuals, organizations, private and public buyers, the urge toward good market positioning (Lichiello \& Madden, 1996), however, it is evident that in this particular period in the health sector in R. Macedonia, laws and regulations are continuous pressure that initiate changes to happen.

Information transfer, standardized, and computerized ways of record keeping, supported by compatible IT resources are recommended to help standardize work with patients as well as evaluate outcomes and continuity of care (McLaren et al., 2013). The majority of the respondents had a positive attitude regarding introducing a 
new IT system adapted to the needs of accreditation, which shows that they perceive this important link for interconnecting and fast and effective sharing information at all levels in the organization.

Positive changes in organizations do happen even without accreditation, it has been answered by the respondents which have significant difference versus respondents with negative answer and without opinion. This leads to the conclusion that it is difficult to distinguish that organizational changes are exclusively the result of accreditation, although it is one very influential factor. When professionally controlled evaluation was initiated in 1917 (Alkhenizan \& Shaw, 2011), it could not be predicted that it should serve the needs of the government, the public, and other purchasers (Schyve, 2000). Yet, the mechanism of accreditation as it evolves tends to include more than previously, representatives from the public and the government, for standards and policies to improve according to actual needs and to initiate organizational changes which will be recognized as ones which lead to better quality of healthcare compared with those changes which happen without introducing accreditation. It makes a significant difference if a healthcare organization has a culture which supports quality and an approach of all the flexible ways of its implementation, versus plain matching of the healthcare organization with predetermined criteria (Shortell et al., 1995). In that way, the readiness of the healthcare organization for adaptation to conditions dictated from various external and internal factors becomes much bigger. Lack of organizational readiness for change may account for as many as half of all unsuccessful change initiatives (Kotter, 1996; Holt, Armenakis, Harris, \& Field, 2007). Resistance toward changes in this study regarding the answers of the respondents has no significant statistical difference in the perceptions having versus not having resistance and without opinion. Prior research has shown that early perceptions and beliefs play a central role in shaping future attitudes and behaviors such as negative rumours, involvement in the planning and design phases, and resistance (Paré, Sicotte, Poba-Nzaou, \& Balouzakis, 2011). Understanding the factors which affect organizational changes can lower resistance toward them.

More than half of the respondents believe that the most important changes due to accreditation happen in the working conditions, which was the predominant answer also from the doctors without managerial function. The role of accreditation is, to contribute to achieving better working conditions and healthier working environment, in order to improve the well-being of the working personnel in healthcare organization (Nicklin \& Barton, 2007). It is recognized that the health service environment is one of the most difficult within which to work. It is physically and emotionally demanding and poses a high risk of injuries, potential violence over healthcare workers as well as limited control over workload and work schedules (Nicklin \& Barton, 2007).

Respondents in this study believe that accreditation is an effective tool for an organization to implement changes which lead to quality. Percentage difference registered between the modalities yes vs. no and without answer is statistically significant. The perceptions that accreditation as a process can lead to improving quality in healthcare organizations, leads to the conclusion that this process will be embraced by the healthcare providers as a process which can shape many aspects of the work in the healthcare organization in positive way. Improving the working environment results with better quality of the working life and that directly positively reflects the quality of services delivered to the patients/clients (Nicklin \& Barton, 2007).

The results of cross tabulation showed that professional function performed by the respondents has no significant impact on their views on organizational changes and their connection to the process of accreditation as indicated, except in the view concerning the impact of accreditation on working conditions given by the doctors without managerial function . 
The results of logistic regression analysis showed that significant predictors for predicting a positive attitude toward effective accreditation are gender of respondents, perception on management as the driver toward changes in the organization, and the attitude toward introduction of a new information system adapted to the needs of accreditation.

\section{Conclusions}

This study finds interrelation of the perceptions of healthcare providers, to variables regarding organizational changes related to accreditation in the context of improving quality in a period before introducing national accreditation in the R. Macedonia. We can conclude that variables such as changes in line with law and regulations, introducing a new informational system or intranet, improving the working conditions, are perceived by the majority of the respondents as drivers toward successful implementation of the process. On the other hand, high percent of the respondents find positive changes happen even without introducing accreditation. Personnel are not certain who leads the changes. To them, in almost equal number, it is the management, the expert team, and other. Personnel is also not conclusive if resistance to change exists depending on the nonsignificant answers yes, no, and without answer.

One of the goals of the agency of accreditation is to support, instruct, and educate the managers of the healthcare institutions about accreditation and they in turn have to do the same to their expert team in order to make believe in the positive impact of accreditation, to intercept resistance toward changes and to put them to serve toward the goal of quality. The results showed that professional function performed by the respondents has no significant impact on their views on organizational changes and their connection to the process of accreditation as indicated below.

Majority of the respondents answered that they believe accreditation is an effective tool for implementing the changes that lead to quality in their organization. The perception that accreditation as a process will lead to changes that improve the quality or services in health organizations shows that the process has the prerequisite to achieve this positive outcome.

As a whole, we may conclude that implementing organizational changes requires time and resources, and accreditation may serve as a tool that encourages improved collective performance of a health care organization in her goal toward providing higher quality of healthcare services as perceived by the majority of healthcare givers in our study. Accepting an obligatory accreditation in healthcare in R. Macedonia will drive the institutions toward changes. This study is expected to influence consciousness of healthcare staff about accreditation as a driving force toward positive organizational changes. Further studies will show if these changes are perceived as truly positive and leading to improved quality. Also, future studies may compare perceptions during and after accreditation of the healthcare institutions in R. Macedonia.

\section{References}

Alkhenizan, A., \& Shaw, C. (2011). Impact of accreditation on the quality of healthcare services: A systematic review of the literature. Ann Saudi Med., 31(4), 407-416.

Braithwaite, J., Westbrook, J., Johnston, B., Clark, S., Brandon, M., Banks, M., ... Moldovan, M. (2011). Strengthening organizational performance through accreditation research-a framework for twelve interrelated studies: The ACCREDIT project study protocol. BMC Research Notes, 4(390).

Braithwaite, J., Westbrook, J., Pawsey, M., Greenfield, D., Naylor, J., Iedema, R., ...Gibberd, R. (2006). A prospective, multi-method, multi-disciplinary, multi-level, collaborative, social-organisational design for researching health sector accreditation. BMC Health Services Research, 6(113). 
Collopy, B. T. (2000). Clinical indicators in accreditation: An effective stimulus to improve patient care. Int J Qual Health Care, 12(3), 211-216.

Drew, M. P. (2005). CCHSA Accreditation: A catalyst for change and building block for social capital. Health Administration School of Management, University of Ottawa, Canada.

Greenfield, D., \& Braithwaite, J. (2008). Health sector accreditation research: A systematic review. Int J Qual Health Care, 20, 172-183.

Greenfield, D., Pawsey, M., \& Braithwaite, J. (2010). What motivates professionals to engage in the accreditation of healthcare organizations? Int. Journal for Quality in Health Care, 23(1), 8-14.

Holt, D., Armenakis, A., Harris, S., \& Field, H. (2007). Toward a comprehensive definition of readiness for change: A review of research and instrumentation. Research in Organizational Change and Development, 16, 289-336.

Huang, P., Hsu, Y.-H. E., Kai-Yuan, T., \& Hsueh, Y.-S. (2000). Can European external peer review techniques be introduced and adopted into Taiwan's hospital accreditation system? International Journal for Quality in Health Care, 12(3), 251-254.

Kotter, J. (1996). Leading change. Boston, MA: Harvard Business Press.

Lichiello, P., \& Madden, C. W. (1996). Context and catalysts for change in health care markets. Health Aff (Millwood), 15(2), 121-129.

McLaren, S., Belling, R., Paul, M., Ford, T., Kramer, T., Weaver, T., ... Singh, S. P. (2013). "Talking a different language”: An exploration of the influence of organizational cultures and work practices on transition from child to adult mental health services. BMC Health Serv Res., 13(254).

Moe, J. L., Pappas, G., \& Murray, A. (2007). Transformational leadership, transnational culture and political competence in globalizing health care services: A case study of Jordan's King Hussein Cancer Center. Global Health, 3(11).

Nicklin, W., \& Barton, M. (2007). CCHSA accreditation: A change catalyst toward healthier work environments. Health Pap., 7(special issue), 58-63.

Pahkin, K., Nielsen, K., Väänänen, A., Mattila-Holappa, P., Leppänen, A., \& Koskinen, A. (2014). Importance of change appraisal for employee well-being during organizational restructuring: Findings from the Finnish paper industry's extensive transition. Industrial Health, 52(5), 445-455.

Paré, G., Sicotte, C., Poba-Nzaou, P., \& Balouzakis, G. (2011). Clinicians' perceptions of organizational readiness for change in the context of clinical information system projects: Insights from two cross-sectional surveys. Implement Sci., 6, 15.

Ripley, V. L. (2007). Fostering an environment of continuous quality improvement. Royal Roads University, Canada.

Schyve, P. M. (2000). The evolution of external quality evaluation: Observations from the Joint Commission on Accreditation of Healthcare Organizations. Int J Qual Health Care, 12(3), 255-258.

Shortell, S. M., O’Brien, J. L., Carman, J. M., Foster, R. W., Hughes, E. F., Boerstler, H., \& O’Connor, E. J. (1995). Assessing the impact of continuous quality improvement/total quality management: Concept versus implementation. Health Services Research, 30(2), 377-401.

Tosh, A. E. (2006). CCHSA accreditation: An investigator for change and a motivator for health human resources. Health Administration School of Management, University of Ottawa, Canada. 